\title{
A Critical Review of Leonhard Praeg's A Report on Ubuntu $^{1}$
}

\author{
TITLE: A Report on Ubuntu
}

AUTHOR: Leonhard Praeg

Pietermaritzburg: University of KwaZulu-Natal Press, 2014

\author{
ISBN: 978-1-86914-256-8
}

\section{PAPERBACK: $\$ 37.00$}

\author{
Reviewed by Reginald M.J. Oduor \\ Department of Philosophy and Religious Studies \\ University of Nairobi, Kenya \\ rmjoduor@gmail.com
}

DOI: $\underline{\text { http://dx.doi.org/10.4314/tp.v6i2.6 }}$

Thought and Practice: A Journal of the Philosophical Association of Kenya (PAK)

New Series, Vol.6 No.2, December 2014, pp.75-90

thoughtandpractice@gmail.com

http://ajol.info/index.php/tp/index

ISSN: 2076-7714

\footnotetext{
${ }^{1}$ I am deeply grateful to my senior colleague and friend, Prof. Okoth Okombo, for his very helpful comments on my presentation of the linguistic aspects of the term 'Ubuntu'.
} 


\begin{abstract}
This article opines that in view of its detailed presentation of the contemporary discourse on Ubuntu, its incisive analysis of key concepts in this discourse, as well as its bold and thoroughgoing critique of the assumptions of both the advocates of Ubuntu and the defenders of the hegemonic Western liberal tradition, Leonhard Praeg's seminal work, A Report on Ubuntu, is an outstanding contribution not only to the Southern African discourse on Ubuntu, but also to the ongoing quest for methodology in African philosophy as a whole.
\end{abstract}

\title{
Background
}

The word Ubuntu is now widely known and used far beyond its linguistic cradle of subSaharan Africa. Hearing it on the lips of some South African judges in the course of crucial judgments, the Liberian peace activist Leymah Gbowee, Former U.S. Special Representative for Global Partnerships Elizabeth Frawley Bagley, former U.S. President Bill Clinton, and current U.S. President Barak Obama, as well as its centrality in John Boorman's 2004 film "In My Country" is sufficient evidence that it has obtained a life of its own, and is now staking its claim in the global socio-political discourse. It comes from the so-called Bantu languages of sub-Saharan Africa, all of which refer to a 'person' using a version of a word which is surfixed by the vowel $t u, d u$, to pronounced ("toe"), or thu. Thus we have muntu (Zulu), muthu (among some communities in Malawi), moto among some communities in the Democratic Republic of Congo, mundu (in several Kenyan languages such as Kikuyu, Kikamba and Kimeru), and Mtu (in Kiswahili).

Scholars of linguistics inform us that grammatically, the word Ubuntu combines the root -ntu ("person" or "human being") with the class $14 u b u$ - prefix used to form abstract nouns, so that the term is exactly parallel in semantic content to the abstract noun 'humanity'. It can also be transliterated as "human-ness". We find variations of the word in different Bantu languages, such as the Shona $u n h u$, among some communities in Malawi uMunthu, and the Kiswahili utu. In practice however, ubuntu has come to refer to 'a humanitarian outlook', 'humanism' or 'socialism', all presumably in contradistinction to capitalism, with emphasis on the moral obligation of the individual to acknowledge and respect other human beings in view of the inescapable interdependence among humankind. Thus Ubuntu is often presented as a version of African communalism or African socialism, both of which are viewed as 
forms of humanism. This is reminiscent of the fact that at the height of Julius Nyerere's Ujamaa ("familihood" - "African Socialism") experiment in the early 1970s, Radio Tanzania had a promotional piece, just before or after every prime news broadcast, that stated that "Ujamaa ni utu, ubepari ni unyama" ("Socialism is humanitarian, capitalism is brutish"). Indeed, ubuntu, as an ideological or philosophical position, falls squarely in the tradition of political and scholarly discourses that advocate for the creation of contemporary societies founded on indigenous African communalism.

In line with the idea of 'sharing', the term 'Ubuntu' has been further popularised by a variant of an Open Source computer Operating system which adopted the name 'Ubuntu Linux' in October 2004 to highlight the fact that the system was available free of charge. The idea was to create an operating system that people could not only freely use, but could also improve and make their innovations accessible to all to promote a culture of sharing. Indeed, the operating system has to date brought much needed relief to approximately twenty-five million computer users who found the license fees for other operating systems prohibitive or simply out of reach, and their terms of use unbearably rigid (see Gilbertson 2014).

Prof. Leonhard Praeg's seminal book, A Report on Ubuntu, is the third in a series titled "Thinking Africa" prepared by the Department of Political and International Studies at Rhodes University in collaboration with the University of KwaZulu-Natal Press. Previous series titles are The Return of Makhanda: Exploring the Legend by Julia C. Wells (2012) and On African Fault Lines: Meditations on Alterity Politics by V.Y. Mudimbe (2013). Praeg's previous publications include African Philosophy and the Quest for Autonomy: A Philosophical Investigation (2000), The Geometry of Violence: Africa, Girard, Modernity (2007) and Creating Destruction: Constructing Images of Violence and Genocide (co-edited with Nancy Billias, 2011). Prof. Praeg is based at the Department of Political and International Studies, Rhodes University, Grahamstown, South Africa.

\section{Conceptualising the Problem of Ubuntu}

Despite the considerably wide currency of the term Ubuntu and the proliferation of scholarly books and papers on it, there is much that is unclear about its nature and relevance as an ideology or philosophy in the post-apartheid, globalised twenty-first century South Africa, and it is this lack of clarity that Prof. Leonhard Praeg seeks to address in his A Report on Ubuntu. He accuses the African National Congress (A.N.C.) of seeking to violently reduce 


\section{Reginald M.J. Oduor}

humanism to the logic of identity politics (p.xi). According to him, through the Marikana massacre, the illusion of a united nation was revealed for what it really was, and with this revelation an awareness of the severing of the South African polity from the values espoused at the moment of its inception became manifest (p.xii). During that Massacre on $16^{\text {th }}$ August 2012, almost twenty years after the end of Apartheid, members of a contingent of the South African Police Service from an elite unit opened fire with submachine guns (R5 rifles), killing thirty-four striking miners and wounding at least seventy-eight others within minutes at the Marikana platinum mine. The incident was the single most lethal use of force by South African security forces against civilians since the Sharpeville massacre during the apartheid era (on 21st March 1960). The Marikana Massacre was an incident in which an indigenous African-led South African government unleashed lethal violence against its indigenous African citizenry, thus raising fundamental questions about the real foundation of the postapartheid South African polity.

Nevertheless, Praeg insists that instead of despair, South Africans can respond by proceeding from a temporary suspension (epoché) of the nationalist matrix and all the dead-end questions that have resulted from it (what is African about this communitarianism, this humanism, this socialism? What does African mean?), in order to re-position Ubuntu in the more cosmopolitan terms of a critical humanism that must always remain irreducible to the politics of the day, a project that has to return to, in order to retrace, the founding claim that a politics premised on a shared humanity is, after all, perhaps, possible (pp.xii-xiii).

The author asserts that in the light of a post-Apartheid South African constitution with a clear liberal democratic orientation, to raise the question of Ubuntu as African philosophy or as a cornerstone of an African philosophical practice, with the assumption that whatever it means it may be useful and relevant to the country, is indeed a very complex business, demanding of South African intellectuals not only to ask and answer a philosophical question, but also to interrogate philosophy itself (pp.4-5). In the light of this difficulty, he contends that it is important to undertake an inquiry into the historical conditions for the possibility of asking questions such as:

- What is Ubuntu?

- What does Ubuntu mean?

- What is or should be the place of Ubuntu in a modern South Africa? (p.5). 
According to Praeg, we can formulate the concern above differently by stating that in order to address the question "What is Ubuntu?" it may be useful to suspend, through a temporary bracketing (or epoché), the question itself in order to ask a number of other questions, such as:

- Why are we asking this question now? Why not 300 years ago?

- What difference does the when (we ask the question) make to the what (we give as an answer)?

- Why do the majority of attempts aimed at defining Ubuntu remain blind to their most basic assumption, namely that there is something significant or particular about Ubuntu?

- Is it not possible that Ubuntu is so over-determined by identity politics - by postcolonial questions about what it means to be African, the demand to be unique, to be authentic and so on - that every engagement with Ubuntu is never simply an intellectual investigation, a way of saying things, but first and foremost a way of conducting identity politics, of doing things? (p.5).

The author indicates that the claim that the political is of the highest priority is central to his book, and one that every humanities student in the postcolony should understand and appreciate (pp.5-6). He explains the meaning of this assertion by pointing out that "all philosophies are historically peculiar to the societies that produce them, 'all philosophy is ethnophilosophy', the philosophy of an ethnos or a people and that the political therefore is First Philosophy", because it determines who takes part in a discourse and what the direction of the discourse takes (pp.6-10).

According to Praeg, the most fundamental political matrix that structures the thinking of South Africans about Ubuntu and that needs to be made visible from the start is the tension between the local and the global, a tension that is truly "supercomplex". In his view, new democracies such as South Africa have to renegotiate what may loosely be referred to as the "social contract': they have to rearticulate citizenship in terms of a new understanding of duties, rights and obligations - which in a context of radical pluralism is a complex business. It becomes a supercomplex business when we realise that all of this has to be done in the context of globalisation, marked by the systematic erosion of the power of states and local cultures, in order to meaningfully contribute to our understanding of what these concepts mean (pp.10-11). Furthermore, he asserts, following Wim van Binsbergen (2001), that the reason why Ubuntu is extremely difficult to define is exactly because it is what some complexity theorists would call a glocal (combination of "global" and "local") phenomenon, that is, a phenomenon about which it is impossible to say whether its content derives exclusively from either a local or a global imaginaire. Thus he asserts that "The reason why Ubuntu has been and will remain impossible to define 


\section{Reginald M.J. Oduor}

is precisely because it is an interstitial concept whose meaning has always been and will continue to be a function of the combination of local needs and global expectations" (p.11). Elsewhere he explains that "To call Ubuntu a glocal phenomenon means recognising that global discourses (Christianity, human rights and so on) give a particular expression to the meaning of local traditions such as ubuntu, but in a way that also allows the resulting Ubuntu to feed back into the global discourse as a locally based critique and expansion of those very discourses" (p.37).

Furthermore, for Praeg, the meaning of African humanism - what is called Ubuntu in southern Africa - is constantly reproduced in the complex space between the local need for cultural identity and a global demand for the expansion (and naturalisation) of human rights, by essentially infusing the meaning of these rights with local understandings (p.11). Central to the book is the assertion that "since the start of decolonisation in Africa, these local and global imaginaires have constantly intersected in order to reproduce very different meanings of and for African humanism - at first a form of humanism, then an African kind of socialism and, more recently, a quasi-Christianised theology of reconciliation and forgiveness. It is simply symptomatic of the asymmetrical relations constitutive of the relationship between African postcolonial societies and the West that African humanism in general and Ubuntu in particular will always be framed as a form of humanism, as an African communitarianism, as an Aristotelian virtue ethic, as an African Socialism and so forth” (pp.11-12).

For the purposes of this book, Praeg frames Ubuntu as 'critical humanism'. Within this framework, the word 'critical' refers to the primacy of the political as determinant of interlocutors ("who qualifies to take part in the discourse?")and subject matter ("what exactly will be deliberated upon?”) (p12). While many would assert that Ubuntu is in a sense a form of humanism, Praeg insists that it is not humanism as an autonomous ideology or philosophy to rival Western political and philosophical forms, but rather the sustained praxis of humanising. He places great emphasis on the view that "contrary to the seductions of identity politics, what is unique about Ubuntu is not any epistemological, ontological or even axiological specificity, but simply the fact of its being an actualised communitarian praxis of the humanising" (pp.19-20).

\section{Chapter Synopses}

In the first chapter, titled "A Political Economy of Obligation", the author interrogates precolonial Africa's communalist orientation and its impact on the current discourse on Ubuntu. He argues that much of the confusion and heated disagreements in the discourse about 
Ubuntu is a function of the failure to distinguish clearly between, on the one hand, the precolonial praxis of ubuntu (with an initial lower case ' $u$ '), which was a minimally theorised but deeply communal way of life, and, on the other hand, the contemporary philosophical expression of that praxis, that is, Ubuntu (with an initial upper case 'U'). His analysis is guided by three questions:

- What understanding of being and belonging does ubuntu (precolonial African communalist praxis) offer us?

- What historical conditions have made it possible for us to talk and think about Ubuntu (post-colonial ideological/philosophical expression of precolonial communalist praxis)in the way that we have come to do?

- How are we to understand or interpret those dimensions of ubuntu (precolonial African communalist praxis) that seem at odds with a neoliberal, democratic order?

In Chapter 2, titled "African Modes of Writing and Being", Praeg considers some of the prominent modes of thinking through which the recovery of Ubuntu is conventionally understood and narrated, insisting that the fact that Ubuntu discourse can be subjected to such an analysis of its various implicit political stances is a direct consequence or implication of his central distinction between ubuntu and Ubuntu. He contends that The combination of historical racism and contemporary identity politics has backed Africa into a corner: the colonial denial of the humanity of Africans has prompted African theorists to counter with the universalist claim that "we are human beings like any others" (a claim to sameness), but identity politics demands the contrary, namely, the substantiation of a particularist claim to difference, to the effect that "we are not like everybody else". The question then becomes how to substantiate the former without forfeiting the identity claim embodied in the latter, or how to substantiate the latter in a way that will not amount to contradicting the former. He therefore sets out to explore the different, complex and nuanced ways in which African theorists have struggled to balance these two imperatives. He bemoans what he sees as the political naivety of much Ubuntu discourse that results in many texts on it to read very much like outdated and therefore boring ethnophilosophy. He blames this situation on, among other factors, the intellectual isolation of South Africa from the rest of the continent during the formative years of what would emerge as the subdiscipline of African philosophy, so that many South African intellectuals are unaware that "Ubuntu discourse must be recognised as little more than an as yet underdeveloped and undertheorised latecomer" (p94). 


\section{Reginald M.J. Oduor}

Praeg executes is self-assigned mandate in his second chapter through the idea of "personae", that is, modes of thinking that in literary works are usually represented by specific characters, namely, the Revolutionary, the Archivist, the Conformist, the Cosmopolitan and the Text Worker: "These personae not only reveal different understandings of thinking and ways of being, but also, considered together, present us with something like a coherent field of inquiry. Within this unified field, each persona represents a specific political stance on questions such as: What can we know and what not? What is the status of knowledge about Africa and what kind of agency is possible and impossible in terms of any specific conception of thinking and being Africa(n)?” (p.96).

In his third chapter, "African Socialism", the author uses Julius Nyerere's Ujamaa experiment to illustrate that the Ubuntu discourse in South Africa has a lot to learn from the experiences of other African states that have experimented with the idea of deploying the indigenous African communalistic outlook to the task of formulating an ideology through which to build viable post-colonial African societies. He uses the Ujamaa project to demonstrate the danger of not making visible the constitutive violence of ujamaa/ubuntu when we translate or codify the praxis into an ideology or philosophy. Perhaps one of the most thought-provoking discussions in the book is that found in this chapter under the subtitle of "hypermodernity and the (im)possibility of the founding" (p.148 ff.). In this section, the author focuses on the process through which a group of individuals constitutes itself into a socio-political entity which it refers to as 'a nation'. With copious citations from relevant literature, he contends that at the precise moment of the founding of such an entity, when the collective first speaks on behalf of a 'We', the 'We' does not yet exist. On the contrary, it is only through the iteration of this claim over time - through the regular singing of the national anthem, the celebration of national events, and participation in other related 'national' activities - that the 'We' will eventually come into being, so that the collective can start acting, not as if it were a 'We', but simply as a collective 'We'. In other words, at the time of the founding of a "nation', the phrase "We the people" does not say something about the world; instead, it does something: while making us believe that there is a 'We', it will actually only perform the 'We' into existence over time (p.149).

Yet Praeg insists that the success of the performative claim at the moment of the founding of a 'nation' wholly depends on its not being recognised as such. Any recognition of the vacuity of the constative claim and the superficiality of the performative iteration will threaten with inexecution the founding moment. Where the origin is transparent to itself, where we cannot 
but recognise the performative for what it is, different strategies have to be deployed to effect or execute the founding, one of which is the violence of pure force or enforcement, which, in Praeg's view, is the violence of the Ujamaa project (p.150; see also pp.244-246). For Praeg, advocates of African socialism behave violently when they exclude from their image of precolonial Africa those forms of individualism and stratification, notably class, that complicate the rosy picture they wish to present of such societies (p.154). Praeg asserts that in line with this strategy, Nyerere's version of African Socialism (Ujamaa) filtered out numerous features of precolonial African societies incompatible with socialism in order to filter in the three principles of love, sharing and labour (p.166). Praeg is particularly critical of the Ujamaa villages established under Nyerere's watch in the late 1960s and early 1970s: "In retrospect and through the lens of postmodern irony, the creation of these villages resembles nothing more than the self-conscious construction of a precolonial theme park; large-scale Ujamaa/Ubuntu villages inhabited by people who have increasingly become out of practice with what it means to live communally" (p.171).

Nevertheless, Praeg concedes that Nyerere was in a sense ahead of scientific socialism (Marxism/Leninism) which was in vogue in the African post-colonies in the height of the Cold War. He contends that while Cosmopolitan scientific socialists were content to dismiss as bourgeois Nyerere's attempt at unifying the idealist and materialist conditions of liberty in a more or less coherent ideology, they had little more to offer than the oppressive universalism of another master narrative of Western modernity that reduced every particular struggle to universal class struggle as the means to the realisation of humankind's historically ordained destination (p.174). However, according to Praeg, Ujamaa failed because it could not satisfy the combination of global, nationalist-developmental and identitarian demands of a post-colonial African society such as Tanzania was (pp.174-175).

For Praeg, the debate between liberalism and communitarianism, in which thinkers such as Nyerere freely immersed themselves, is haunted by an incoherence that is a function of the deep structure or axiomatic of Western modernity itself. He contends that there is no liberalism that is not always already a form of communitarianism because every political liberal thinks of him- or herself first and foremost and inescapably in terms of a constitutive attachment to liberalism qua tradition. Earlier in the book, Praeg had asserted: "That we should be presented with a 'debate' between liberalism and communitarianism is a function of a Western binary axiomatic that forces us to choose between two mutually exclusive metaphysics: that the individual is prior to society or that society is prior to the individual - a 


\section{Reginald M.J. Oduor}

Trojan Horse that is then wheeled into the African polis, where it contaminates thinking with a belief in two supposedly irreconcilable ontologies - Western individualist and African communitarian. In this way, every attempt African subjects make to think their place in the world is structured in advance by the projection, into their very place of thinking, of a binary that is neither sustainable, nor of their own making. ... to read Ubuntu as a form of communitarianism is already to frame and predetermine in important ways how we present and position ourselves in relation to the question of its constitutive violence" (p.23).

In the last two chapters, the author seeks to address the question of how we conceive the emancipatory potential of Ubuntu in the context of a Western-type constitutional order with its emphasis on the primacy of the individual over the community. He argues that when it comes to the law, we need to ask, not what Ubuntu means, but rather, how to position this glocal articulation of our shared humanity in relation to a constitutional regime of individual rights, in order to maximise its emancipatory potential. Praeg calls on us to join him in suspending judgment about two things. The term he uses for this suspension is "epoché", which, he informs us, is the Greek term for cessation or stoppage; hence, in the philosophy of the sceptics, the suspension of judgement (p.194).

The first epoché, Presented in Chapter 4, has to do with colonialism, where he asserts that "...the problem of Ubuntu is, in a complex but very important sense, irreducible to the problem of colonialism as such. By this I mean that, at a very general level, Ubuntu discourse is first and foremost, in its most fundamental form (arche), a confrontation with modernity and the dual fragmentation of individual and social that marks the modern moment" (pp.197198). In other words, he is calling on us to realise that even if Europe had not colonised Africa, modernity would have flooded the continent, and this would have raised questions about Ubuntu very similar to the ones we usually assume arise out of the advent of colonialism. This is due to the fact that modernity as such causes us to be grossly aware of our individuality and to question the idea of interdependence or belonging (p.198).

Furthermore, Praeg contends that while Ubuntu is often defined by juxtaposing the dictum "I am because we are" with the Cartesian "I think therefore I am", Western thought is no longer represented by that dictum: "Why compare a contemporary Ubuntu conception of personhood with a Western, modernist notion of personhood that is 300 years old? Why legitimise the novelty and (always suggested) superiority of the Ubuntu notion of personhood with a Western conception of personhood that, as influential as it may have been for a long time, is no longer representative of how personhood is thought of in the West? Western 
thought about personhood has gone far beyond Descartes in a range of ways, articulating the self in relation to others and the world in ways that now bear very little resemblance to the sovereign cogito articulated by Descartes. In fact, certain post-Cartesian understandings of personhood, such as we find in Martin Heidegger's ontological hermeneutics and various forms of communitarianism, particularly feminist ethics of care, are not only indistinguishable from Ubuntu but, given the logic of retrodiction, often essential for the articulation of Ubuntu. Why, then, this historically disjunctive comparison?" (pp.207-208). He highlights the danger of accepting the narrative that communitarianism is distinctly African, for it enables the neo-liberal West to avoid interrogation on the basis that Africa is uniquely capable of communitarianism while the West is pathologically incapable of it, thereby concealing the fact that there is a strong, centuries-old communitarian outlook in Western society as well (p.219).

According to Praeg, the second epoché, whose implications he explores in Chapter 5, is necessitated by the realisation that the founding of post-Apartheid South Africa will for ever be haunted by the fact that unlike Western modernity, it entailed what he refers to as "hypermodernity" - "the spectre of a founding that will remain eternally exposed, visible to itself and therefore, inexecuted" (p.223). He asserts that if the first epoché revealed modernity as the moment when belonging becomes a problem for thought, the second epoché reveals that the tension between individualism and communitarianism is at the heart of what belonging is taken to mean in modern legal cultures, which is to say that it is not peculiar to post-colonial African states. The important insight that the so-called tension between the contractual axiomatic of the post-Apartheid South African Constitution and the communitarian axiomatic of Ubuntu (the so-called problem of conflicting Western and African ontologies) is not unique, not exceptional or even particularly problematic because it is principally a tension between individualist and altruist tendencies, constitutive of modern legal cultures (p.229). Nevertheless, he bemoans the fact that in the context of post-colonial African states, "The playing field between individualist and altruistic tendencies is not level, but rather, as a direct result of colonialism, skewed in favour of individualism. Standards, histories, customs and habits; that is, forms of life that represent the altruistic, social or communitarian, are and continue to be fundamentally marginalised and instituted against" (p.239).

However, at the end of my careful reading and re-reading of the section titled "A Second Epoché", I could not identify a categorical formulation of it (the second epoché). Nevertheless, 


\section{Reginald M.J. Oduor}

I concluded that it has to do with suspending the judgment that the tension between individualism and altruism must be viewed from the perspective of identity politics that results in a cleavage between African communalism and Western liberalism. Indeed, Praeg asserts that the second epoché reveals that “... modernity is constituted, first and foremost, as the tension between individualism and altruism, writ large at an institutional level” (p.238).

In a section titled "A return to particularity" (p.242 ff.), Praeg asserts that "One of the most difficult things about conceiving the emancipatory potential of Ubuntu relates to questions of positioning; that is, on having clarity on three related issues. First, what do we mean by emancipation? Second, how do we position Ubuntu in such a discourse of emancipation? Third, once we have decided on its position, what meaning do we attribute Ubuntu, in order for it to contribute to the project of emancipation from the position attributed to it?" (p.242). For him, when we talk about emancipation we refer, at a minimum, to correcting the lack of symmetry in the institutional representation of the fundamental contradiction (p.243).

\section{Critique}

My assessment is that Praeg's central argument in this book is that South African scholars must recognise that there is nothing quintessentially unique about Ubuntu, for it is simply an expression of an altruistic position in response to the tension, found in any modern society, between altruism and individualism: “... the power of and fascination with Ubuntu derive to a large extent from the fact that it ascended in a decidedly post-Cold War moment, when all other ideological alternatives to capitalism that, alongside capitalism, used to remind us of our fundamental interdependence, seem to have lost ideological momentum. In the global imaginaire, Ubuntu steps into this tired place in order to remind us of our shared humanity" (pp.247-248). In addition, he makes the important point that the very nature of the postApartheid South African state, with its liberal constitution, renders a return to ubuntu (the precolonial communalist praxis) virtually impossible: "the Constitution is at once the most lasting trace of colonialism and the culmination of the struggle against colonialism. As such, its founding marks, not only the gain or the beloved 'bridge' of much constitutional jurisprudence of the late 1990s, but also the simultaneous loss of the very possibility of ever restoring the original injustice ..." (p.257). The tenor of the book is a call to intellectuals interested in the contemporary discourse on Ubuntu to undertake incisive reflection on the implications of these two facts instead of incessantly engaging in a conflation of key concepts associated with the discourse and/or indulging in the sterile serenade of precolonial Africa's 
prestine communalism and contemporary Africa's trajectory towards an unprecedented renaissance.

Praeg's A Report on Ubuntu is highly commendable on at least five grounds.

First, in line with a genuine philosophical inquiry and in contrast to a number of publications on Ubuntu in particular and African philosophy in general, the author clearly indicates his self-assigned task (a critical evaluation of the contemporary discourse on Ubuntu), spells out his approach to the task at hand, gives clear definitions of key terms, provides useful background information, and offers cogent arguments for his claims, thereby encouraging African and Africanist scholars to move further away from the polemics on the existence and nature of African philosophy to the more worthwhile task of actually doing African philosophy.

Second, through his incisive critique of the contemporary discourse on Ubuntu, Praeg provides the student of African philosophy with a model for liberating himself/herself from the doctrinaire approach to the sub-discipline, in which doubtful or outrightly false dichotomies are often the stock in trade - African traditionality versus Western modernity, African communalism versus Western liberalism, and African philosophy as worldview versus Western philosophy as critique. He has therefore made a valuable contribution to the body of literature that encourages a universalist approach to African philosophy without disregarding the peculiar perspectives and modes of expression that the African cultural context offers (see for examples Wiredu 1980, 1998; Hountondji 1983; Oruka ed. 1991; Masolo 2010).

Third, the author deploys his outstanding grasp of the history of both African and Western philosophy, as well as his knowledge of the current discourse on globalisation, to the task of explicating and critically examining the place of Ubuntu in the South Africa of the twentyfirst century. He challenges his fellow South African intellectuals to recognise that far from being a peculiar product of their exceptional intellectual acumen, Ubuntu is part of the discourse on the possibility of using indigenous African communalism as the foundation for an ideology by which to create truly humanistic contemporary African societies, and must therefore learn from the errors of those who have trodden this path before them. As one Luganda saying goes, "A man who does not travel thinks that only his mother knows how to cook." 
Fourth, the author's distinction between ubuntu (pre-colonial communal praxis) and Ubuntu (contemporary political and philosophical discourse on that praxis) sheds important light on the distinction between, on the one hand, a worldview of a community, and, on the other, a philosophical discourse arising out of it. Indeed, the failure of many African and Africanist scholars to recognise this important distinction largely accounts for the way African worldviews have been presented as standing shoulder to shoulder with individualised, critical philosophies of Western thinkers. More than half a century ago, George Orwell shed a spotlight on the way in which political language easily obscures or outrightly distorts important facts (Orwell 1946). Since, as Praeg argues, every philosophy is ultimately a political expression, it is no wonder that this kind of conflation is rampant among enthusiastic advocates of African philosophy, but there is no reason why it should be nurtured by avid seekers of truth and justice. Indeed, Praeg's use of the 'suspension of judgment' (epoché) to illustrate that certain issues that we have come to view as consequences of, and therefore inextricably bound up with, colonialism (modernity and the supposed individualistcommunalist dichotomy) are actually concerns with which human societies all over the world have to deal, is a paradigm case of philosophy as a second order activity - an instance in which, as it is sometimes put, the philosopher finds problems where others find none.

Fifth, Praeg's meticulous, nay, clinical, adherence to the canons of scholarly writing is admirable. While many writers articulate a number of ideas that are evidently not original as though they were their own novel perspectives, he is keen to acknowledge his debt to others not only in terms of ideas, but also with regard to terminology. In addition, he provides numerous explanatory footnotes, thus enhancing the reader's comprehension of the discussion. He therefore serves as a role model for upcoming scholars.

One of the key shortcomings of this book is the author's highly sophisticated way of expressing complex ideas - a fact which renders the text unnecessarily difficult to follow for the vast majority of African scholars for whom English is a second, or even a third language. In this regard, it is noteworthy that in the "Acknowledgements", the author tells us that the book was born of a failure to make himself understood In his article titled "An Answer to the Question, 'What is [Ubuntu]?"' (Praeg 2008) intended as the first instalment of a two-part essay on the topic. Perhaps a compactness of language in that article similar to the one in the book largely explained that communication gridlock. Nevertheless, the author's style gives the reader the opportunity to get accustomed to reading intricately structured texts. Indeed, I 
frequently tell my students that the only way to learn how to read philosophical works is by getting on with the task of reading them, and that often one has to read a philosophical text a number of times before one adequately understands it. African scholars must therefore not pamper themselves by refraining from reading this highly informative and thought-provoking book on the excuse that it is difficult to read.

A second shortcoming of the book has to do with the term 'report' in its title. The author himself describes the title as "curiously officious" (p.1). The term 'report' introduces an unnecessary ambiguity in the reader's mind with regard to what to expect from the book, as he/she wonders whether or not he/she is about to be treated to a highly descriptive account of the discourse on Ubuntu after the manner of a journalistic piece, or to a cold, highly formal write-up reminiscent of an official report such as may be commissioned by a personage in government. It turns out that neither of the two kinds of text is to be found in the book, but rather a thoroughgoing critique of contemporary discourse on Ubuntu. Consequently, the title of the book exposes it to the risk of being bypassed by scholars who would benefit immensely from it.

Nevertheless, in view of its detailed presentation of the contemporary discourse on Ubuntu, its incisive analysis of key concepts in this discourse, its bold and thoroughgoing critique of the assumptions of both the advocates of Ubuntu and the defenders of the hegemonic Western liberal tradition, the book is an outstanding contribution not only to the Southern African discourse on Ubuntu, but also to the ongoing quest for methodology in African philosophy as a whole. If you are looking for a book that uncritically sings the virtues of a romanticised African past and a glorious contemporary African Renaissance, this book is not for you; but if you are looking for a paradigm for incisive philosophical reflection in an African context, then you cannot afford not to read this book. 


\section{References}

Gilbertson, Scott. 2014. "Ten years of Ubuntu: How Linux's beloved newcomer became its criticized king". Ars Technica, $23^{\text {rd }}$ October 2014. http://arstechnica.com/informationtechnology/2014/10/ten-years-of-ubuntu-how-linuxs-beloved-newcomer-became-itscriticized-king

Hountondji, P.J. 1983. African Philosophy: Myth and Reality. With an Introduction by Abiola Irele. London: Hutchinson and Co. Ltd.

Masolo, D.A. 2010. Self and Community in a Changing World. Bloomington: Indiana University Press.

Oruka, H. Odera. ed. 1991. Sage Philosophy: Indigenous Thinkers and Modern Debate on African Philosophy. Nairobi: African Centre for Technology Studies.

Orwell, George. 1946. "Politics and the English Language". www.mtholyoke.edu/acad/intrel/orwell46.htm

Praeg, Leonhard. 2000. African Philosophy and the Quest for Autonomy: A Philosophical Investigation. Amsterdam: Rodopi.

--. 2007. The Geometry of Violence: Africa, Girard, Modernity. N.P.: SUN Press.

--. 2008. “An Answer to the Question, 'What is [Ubuntu]?'” South African Journal of Philosophy, Vol.27 No.4.

Praeg, Leonhard and Nancy Billias eds. 2011. Creating Destruction: Constructing Images of Violence and Genocide. Amsterdam: Rodopi.

Van Binsbergen, W. 2001. 'Ubuntu and the Globalisation of Southern African Thought and Society'. Quest 15(12): 54-89.

Wiredu, Kwasi. 1980. Philosophy and an African Culture. Cambridge: Cambridge University Press.

--. 1998. “Toward Decolonizing African Philosophy and Religion”. African Studies Quarterly: The Online Journal for African Studies, Vol.1 Issue 4.

www.africa.ufl.edu/asq/v1/4/3.htm 